\title{
Growing Beyond Survival: Resilience, Hope and Meaning in Life
}

\author{
$\mathrm{Nidhi}^{1 *}$
}

\section{ABSTRACT}

Resilience in the ability to bounce back in the face of adversity. Some people become overwhelmed by life`s challenges and tragedies, while some others seem to maintain their bearings in the face of adversity. Research has indicated that resilient people generally use effective coping strategies, have a firm understanding of reality, a deep and meaningful belief system, the ability to improvise and have a strong belief in the future. Hope includes the ability to motivate oneself and persist in the face of difficult situation while Meaning in life helps in positive coping and adaptation. The purpose of the present investigation is to study the relation between meaning in life, hope and resilience. A sample of 60 subjects (30 males and 30 females), the age range of 18-30 years were administered the Connor-Davidson Resilience Scale (CD-RISC), Adult Hope scale (Snyder) and Meaning in life Questionnaire (Steger, 2006). Suitable statistical technique to be used to study the relationship between the three variables.

Keywords: Resilience, Hope, Meaning in life, Adversity, Strategies.

Growing beyond survival is a self-management workbook, which teaches skills that empower survivors to take control of and de-escalate their most distressing trauma related symptoms. It teaches trauma survivors to recognize, contextualize, and understand distressing dissociative and posttraumatic reactions. It also creates a structure in which to learn and practice skills for selfregulation of the troublesome thoughts, feelings, and impulses related to traumatic experience. Growing beyond Survival integrates concrete techniques for regulating emotions into a systematic approach for enhancing self-awareness.

\section{Resilience}

Resilience is defined as an individual's ability to properly adapt to stress and adversity. Stress and adversity can come in the shape of family or relationship problems, health problems, or workplace and financial stressors, among others. Individuals demonstrate resilience when they can face difficult experiences and rise above them with ease. Resilience is not a rare ability; in reality, it is found in the average individual and it can be learned and developed by virtually

\footnotetext{
${ }^{1}$ Research scholar, Department of Psychology, M.D.U. Rohtak

*Responding Author

(c) 2016 I Nidhi; licensee IJIP. This is an Open Access Research distributed under the terms of the Creative Commons Attribution License (http://creativecommons.org/licenses/by/2.0), which permits unrestricted use, distribution, and reproduction in any Medium, provided the original work is properly cited.
} 


\section{Growing Beyond Survival: Resilience, Hope and Meaning in Life}

anyone. Resilience should be considered a process, rather than a trait to be had. There is a common misconception that people who are resilient experience no negative emotions or thoughts and display optimism in all situations. Contrary to this misconception, the reality remains that resiliency is demonstrated within individuals who can effectively and relatively easily navigate their way around crises and utilize effective methods of coping. In other words, people who demonstrate resilience are people with positive emotionality; they are keen to effectively balance negative emotions with positive ones.

Resilience is composed of particular factors attributed to an individual. There are numerous factors, which cumulatively contribute to a person's resilience. The primary factor in resilience is having positive relationships inside or outside one's family. It is the single most critical means of handling both ordinary and extraordinary levels of stress. These positive relationships include traits such as mutual, reciprocal support and caring. Such relationships aid in bolstering a person's Resilience. Resilience is best understood as a process. It is often mistakenly assumed to be a trait of the individual, an idea more typically referred to as "resiliency. Most research now shows that resilience is the result of individuals being able to interact with their environments and the processes that either promote well-being or protect them against the overwhelming influence of risk factors. Dumont \& Widom (Sep, 2014). Found that stressful life events and a supportive partner promoted resilience in young adulthood. Neighborhood advantage did not exert a direct effect on resilience, but moderated the relationship between household stability and resilience in adolescence and between cognitive ability and resilience in young adulthood. Wang \& Walberg (2010) one factor found to contribute to resilience was the development of a significant relationship with a family member or adult member. More recently, the focus of resilience has been extended to the family unit. These processes can be individual coping strategies, or may be helped along by good families, schools, communities, and social policies that make resilience more likely to occur. In this sense "resilience" occurs when there are cumulative "protective factors". These factors are likely to play a more and more important role the greater the individual's exposure to cumulative "risk factors". When a person faces stress and adversity, especially of a repetitive nature, their ability to adapt is an important factor in whether they have a more positive or negative outcome. Resilient individuals are those who are considered to have positive developmental outcomes in light of their negative experiences, such as bullying. Sapouna \& Wolke (2013) examined adolescents who illustrated resilience to bullying and found some interesting gendered differences, with higher behavioral resilience found among girls and higher emotional resilience found among boys. Despite these differences, they still implicated internal resources and negative emotionality in either encouraging or being negatively associated with resilience to bullying respectively and urged for the targeting of psychosocial skills as a form of intervention. Schneider et al. (2013) found that emotional perception was significant in facilitating lower negative emotionality during stress and Emotional Understanding facilitated resilience and has a positive correlation with positive affect. Fostering resilience in children requires family environments that are caring and stable, hold high expectations for children's behavior and encourage participation in the life of the family. Most 


\section{Growing Beyond Survival: Resilience, Hope and Meaning in Life}

resilient children have a strong relationship with at least one adult, not always a parent and this relationship helps to diminish risk associated with family discord. Benard (2010) found that even though divorce produces stress, the availability of social support from family and community can reduce stress and yield positive outcomes. Any family that emphasizes the value of assigned chores, caring for brothers or sisters, and the contribution of part-time work in supporting the family helps to foster resilience.

There is significant research found in the literature on the relationship between positive emotions and resilience. Studies show that maintaining positive emotions whilst facing adversity promote flexibility in thinking and problem solving. Tugade \& fredrickson (2012) suggest that resilient people may use positive emotions strategically or intelligently to achieve their superior coping outcomes. Positive emotions serve an important function in their ability to help an individual recover from stressful experiences and encounters. That being said, maintaining a positive emotionality aids in counteracting the physiological effects of negative emotions. It also facilitates adaptive coping, builds enduring social resources, and increases personal well-being.

\section{Meaning in Life}

Human beings have a strong desire to understand themselves and the world around them, exhibiting cognitive and behavioral activity in support of such desires (Vohs, 2006; Higgins, 2000).People theoretically experience the presence of meaning when they comprehend themselves and the world, understand their unique fit in the world, and identify what they are trying to accomplish in their lives . Thus, people are thought to be motivated both to have and search for meaning in life. However, people vary in the degree to which they actively search for meaning. We define the search for meaning in life as the strength, intensity, and activity of people's desire and efforts to establish and/or augment their understanding of the meaning, significance, and purpose of their lives. In some theories, the search for meaning is seen to be a positive sign of mental health; in other theories, quite the opposite perspective is proposed. Frankl (2005; \& Maddi, 2009) wrote that searching for meaning is "the primary motivational force in man [sic]". As such, the search for meaning should be a natural, healthy part of life, spurring people to seek out new opportunities and challenges, and fueling their desire to understand and organize 200 Steger, Kashdan, Sullivan, et.al.their experiences. In contrast, other accounts regard search for meaning as symptomatic of dysfunction. For example, Baumeister (2009) and Klinger (2011) have suggested that the search for meaning only occurs among individuals whose needs have been frustrated. A third perspective recognizes both possibilitiesthat search for meaning has both healthy (i.e., life-affirming) and unhealthy (i.e., deficit-based) motivational roots (Reker, 2000). Finally, we propose a previously unexplored possibility that search for meaning might arise from different underlying motivations in different people and thus have different correlations depending on those motivations. 


\section{Hope}

A typical dictionary definition of hope as "a desire and the confident expectation of its fulfillment" captures one of the fundamental reasons that humans enjoy sporting activities (Osterhoudt, 1978). Nevertheless, the role of hope has remained unexplored among personality researchers interested in individual differences in motivation, as well as by sport psychologists, largely because a theoretical model of hope and the associated measurement instruments have not been available. Previously, scholarly writings have defined hope as a one-dimensional construct involving an overall perception that goal scan be met (French, 1952; Lewin, 1935; Stotland, 1969). Expanding on this one-dimensional model, Snyder and his colleagues (Snyder, 1994a, 1994b; Snyder, Harris, et al., 1991; Snyder, Sympson, et al., 1996) have suggested that Hope is defined as the perceived capability to derive pathways to desired goals, and motivate oneself via agency thinking to use those pathways. The adult and child hope scales that are derived from hope theory are described. Hope theory is compared to theories of learned optimism, optimism, self-efficacy, and self-esteem. Higher hope consistently is related to better outcomes in academics, athletics, physical health, psychological adjustment, and psychotherapy. Processes that lessen hope in children and adults are reviewed. Using the hope theory definition, no evidence is found for "false" hope. Goal-directed thinking is made up of two necessary components. First, there

Is a pathway thinking, which reflects the person's capacity to conceptualize one or more avenues by which to arrive at the desired goal? Second, there is agentic thinking, which taps thoughts aimed at initiating and sustaining movement along one's chosen pathways toward a desired goal. In turn, hope reflects the iterative sum of pathways and agentic thinking. More specifically, Snyder, Harris, et al. (1991, p. 571) defined hope as a "cognitive set that is based on a reciprocally derived sense of successful (a) agency (goal-directed determination) and (b) Pathways (planning of ways to meet goals)."

\section{PROBLEM}

1. To study the relation between resilience, hope \& meaning in life among adults.

2.To study the predictive role of demographical variables (gender, rural/ urban, joint \& nuclear family, health ) on resilience, hope \& meaning in life.

\section{Hypothesis}

1. There are significant relation between resilience, hope \& meaning in life.

2. Demographical variables significant prediction of resilience, hope \& meaning in life.

\section{METHOD}

\section{Sample-}

A sample of 60 subjects (30 males and 30 females) within the age range of 18 -30years from Jhajjar was chosen on the basis of availability. Only those students were taken who gave their 
consent and showed their cooperation and interest in the study. The subjects were equated to maximum in terms of socio-demographic variables.

\section{Tools}

The Connor-Davidson Resilience Scale (CD-RISC, 2003) Connor-Davidson Resilience Scale developed by Connor-Davidson. It is consisting of 25 items. Respondents indicated their level of agreement using a 5-point likert scale from strongly disagree (0) to strongly agree (4). The total score was achieved by adding up all responses, and ranges from 0 to 100, with higher scores reflecting greater resilience. The scale showed an adequate internal consistency $(\alpha>.80)$.

Adult Hope Scale (AHS, 2002). Adult hope scale developed by Snyder. It is a self report questionnaire that contains twelve questions. Items are scored on an eight point Likert scale. The scale creates three scores, a hope score that is created by summing the agency and pathway items or two separate scores that measure agency and pathways independently by totaling their respective items. Total hope scale scores range from a minimum of 8 to a maximum of 64, while agency and pathway scores range from a minimum of 4 and a maximum of 32 with high scores reflecting high levels of hope.

Meaning in Life Questionnaire (MLQ). Meaning in life questionnaire developed by Steger in (2006). It is 10-item questionnaire designed to measure two dimensions of meaning in life: (1) Presence of Meaning (how much respondents feel their lives have meaning), and (2) Search for Meaning (how much respondents strive to find meaning and understanding in their lives). It is a 7-point Likert-type scale ranging from 1 (Absolutely True) to 7 (Absolutely Untrue).

\section{Procedure}

Firstly, the subject was seated comfortably in a quiet and well illuminated room. Then the experimenter gave the Connor-Davidson Resilience Scale (CD-RISC), Adult Hope Scale $(\mathrm{ADH})$, Meaning in Life Questionnaire (MEQ). After it detailed instructions for filling up the forms were given. It was ensured that the participants had understood the method of responding to all the inventories. After giving instructions the test was started. Subjects filled all the four scales. After collecting the data, the scoring was done as per the manuals. The data was tabulated and subjected to statistical analyses.

\section{RESULT AND DISCUSSION}

The present investigation sought to assess the relation between resilience, hope \& meaning in life. After computing the mean and S. D.'s for the three parameters the data was subjected to regression analyses. The mean score for total sample on resilience, Hope, and meaning in life have been shown in Table 1. 
Table: 1 Summary Table Showing The Mean And S.D.'S Of Male And Female

\section{Group Statistics}

\begin{tabular}{|l|l|l|l|l|}
\hline \multicolumn{1}{|c|}{} & Gender & N & Mean & Std. Deviation \\
\hline \multirow{2}{*}{ Resilience } & Male & 30 & 62.0000 & 13.59006 \\
\cline { 2 - 5 } & Female & 30 & 60.9333 & 6.56497 \\
\hline \multirow{2}{*}{ Hope Agency } & Male & 30 & 24.7000 & 3.71530 \\
\cline { 2 - 5 } & Female & 30 & 23.8000 & 4.40533 \\
\hline \multirow{2}{*}{$\begin{array}{l}\text { Meaning } \\
\text { (Presence) }\end{array}$} & Male & 30 & 24.9000 & 3.08891 \\
\cline { 2 - 5 } $\begin{array}{l}\text { Meaning } \\
\text { (Search) }\end{array}$ & Female & 30 & 22.0667 & 3.75025 \\
\cline { 2 - 5 } & Fale & 30 & 23.7667 & 3.43093 \\
\cline { 2 - 5 } & Female & 30 & 21.3667 & 4.10621 \\
\hline
\end{tabular}

Table Iii: Summary Table Showing T-Values For Male \& Female Population $(\mathrm{N}=60)$

\begin{tabular}{|c|c|c|c|c|c|}
\hline & $\mathbf{F}$ & Sig. & $\mathbf{t}$ & df & $\begin{array}{l}\text { Sig. (2- } \\
\text { tailed) }\end{array}$ \\
\hline \multirow[t]{2}{*}{ Resilience } & 8.729 & .005 & .387 & 58 & .700 \\
\hline & & & .387 & 41.836 & .701 \\
\hline \multirow{2}{*}{$\begin{array}{l}\text { Hope } \\
\text { Agency }\end{array}$} & .465 & .498 & .855 & 58 & .396 \\
\hline & & & .855 & 56.395 & .396 \\
\hline \multirow{2}{*}{$\begin{array}{l}\text { Hope } \\
\text { Pathway }\end{array}$} & 1.853 & .179 & 3.194** & 58 & .002 \\
\hline & & & $3.194 * *$ & 55.946 & .002 \\
\hline \multirow{2}{*}{$\begin{array}{l}\text { Meaning } \\
\text { (Presence }\end{array}$} & 1.131 & .292 & $2.457 *$ & 58 & .017 \\
\hline & & & $2.457 *$ & 56.223 & .017 \\
\hline \multirow{2}{*}{$\begin{array}{l}\text { Meaning } \\
\text { (search) }\end{array}$} & 3.496 & .067 & 2.461 & 58 & .017 \\
\hline & & & 2.461 & 54.244 & .017 \\
\hline
\end{tabular}

There is no significant difference between in three groups which were used under the present study on resilience, hope and meaning in life (search). A significant difference was found in both male and female on hope pathway and meaning in life (presence). 
Table III: Summary Table showing Intercorrelation matrix

\begin{tabular}{|c|c|c|c|c|c|c|c|c|c|}
\hline \multirow{4}{*}{\begin{tabular}{|l|} 
\\
Family \\
Type
\end{tabular}} & & FT & AREA & Gender & Resilience & HA & HP & MiL.P & MiL.S \\
\hline & (FT) & 1 & .179 & .135 & .073 & -.013 & .178 & .183 & .031 \\
\hline & & & .172 & .305 & .578 & .924 & .173 & .162 & .817 \\
\hline & & & 60 & 60 & 60 & 60 & 60 & 60 & 60 \\
\hline \multirow[t]{3}{*}{ AREA } & & & 1 & -.068 & .067 & -.101 & .106 & -.084 & $-.309^{*}$ \\
\hline & & & & .605 & .609 & .441 & .421 & .526 & .016 \\
\hline & & & & 60 & 60 & 60 & 60 & 60 & 60 \\
\hline \multirow[t]{3}{*}{ Gender } & & & & 1 & .051 & .112 & $.387^{* *}$ & $.307^{*}$ & $.307^{*}$ \\
\hline & & & & & .700 & .396 & .002 & .017 & .017 \\
\hline & & & & & 60 & 60 & 60 & 60 & 60 \\
\hline \multirow[t]{3}{*}{ Resilience } & & & & & 1 & $.320^{*}$ & .115 & .150 & -.005 \\
\hline & & & & & & .013 & .380 & .253 & .968 \\
\hline & & & & & & 60 & 60 & 60 & 60 \\
\hline \multirow{3}{*}{$\begin{array}{l}\text { Hope } \\
\text { Agency } \\
\text { (HA) }\end{array}$} & & & & & & 1 & .158 & .154 & .207 \\
\hline & & & & & & & .229 & .240 & .112 \\
\hline & & & & & & & 60 & 60 & 60 \\
\hline \multirow{3}{*}{$\begin{array}{l}\text { Hope } \\
\text { Pathway } \\
\text { (HP) }\end{array}$} & & & & & & & 1 & .215 & -.031 \\
\hline & & & & & & & & .099 & .811 \\
\hline & & & & & & & & 60 & 60 \\
\hline \multirow{3}{*}{$\begin{array}{l}\text { Meaning } \\
\text { (Presence) } \\
\text { (MIL. P) }\end{array}$} & & & & & & & & 1 & $.470^{* *}$ \\
\hline & & & & & & & & & .000 \\
\hline & & & & & & & & & 60 \\
\hline \multirow{3}{*}{$\begin{array}{l}\text { Meaning } \\
\text { (Search) } \\
\text { (MIL. S) }\end{array}$} & & & & & & & & & 1 \\
\hline & & & & & & & & & \\
\hline & & & & & & & & & 60 \\
\hline
\end{tabular}

*. Correlation is significant at the 0.05 level (2-tailed).

**. Correlation is significant at the 0.01 level (2-tailed).

Result inter-correlational from table 11, reveal that hope pathway is a positive correlate to gender of total sample $(\mathrm{r}=0.387 ; \mathrm{p}<.01)$. Meaning in life's sub-scale presence is positive correlate to gender of total sample $(\mathrm{r}=.307 ; \mathrm{p}<.05)$ and meaning in life (presence) is positively correlate to meaning in life (search) for total sample $(r=.470 ; \mathrm{p}<.01)$. Meaning in life (search) is negatively correlates to area $(r=.309 ; \mathrm{p}<.05)$.

\section{Multiple Regressions:}

Results of step-wise multiple regressions revealed that predictor has been found significant contributor for population of the sample. 
Table Iv: Regression Summary (Dependent Variable- Meaning In Life (Presence)

\begin{tabular}{|l|l|l|l|l|l|l|}
\hline Predictors & $\mathbf{R}$ & $\mathbf{R}^{2}$ & Adjusted $\mathbf{R}^{2}$ & $\mathbf{B}$ & $\boldsymbol{\beta}$ & $\mathbf{F}\left(\mathbf{f o r} \mathbf{R}^{2}\right.$ ) \\
\hline Gender & .307 & .094 & .079 & 2.400 & .307 & 6.035 \\
& & & & & & \\
\hline
\end{tabular}

Whereas, multiple regression results shown in table IV of the total sample which reveals that gender is a predictor of meaning in life (presence) and $9 \%$ of variance is accounted by gender for meaning in life (presence).

Table V: Regression Summary (Dependent Variable- Meaning In Life (Search)

\begin{tabular}{|c|c|c|c|c|c|c|}
\hline Predictors & $\mathbf{R}$ & $\mathbf{R}^{2}$ & \begin{tabular}{|l} 
Adjusted \\
$\mathbf{R}^{2}$ \\
\end{tabular} & B & $\boldsymbol{\beta}$ & $F\left(\right.$ for $\left.R^{2}\right)$ \\
\hline $\begin{array}{ll}\text { Area } & \& \\
\text { Gender } & \end{array}$ & $\begin{array}{l}.309 \\
.422\end{array}$ & $\begin{array}{l}.096 \\
.178\end{array}$ & $\begin{array}{l}.080 \\
.149\end{array}$ & $\begin{array}{l}-3.24 \\
3.15\end{array}$ & $\begin{array}{l}-.290 \\
.280\end{array}$ & 6.035 \\
\hline
\end{tabular}

Whereas, multiple regression results shown in table $\mathrm{V}$ of the total sample which reveals that gender and area is a predictor of meaning in life (search) and 9\% of varience.

Table Vi : Regression Summary (Dependent Variable- Hope Pathway)

\begin{tabular}{|l|l|l|l|l|l|l|}
\hline Predictor & $\mathbf{R}$ & $\mathbf{R}^{2}$ & Adjusted $\mathbf{R}^{2}$ & $\mathbf{B}$ & $\boldsymbol{\beta}$ & $\mathbf{F}\left(\mathbf{f o r} \mathbf{R}^{2}\right.$ ) \\
\hline Gender & .387 & .150 & .135 & 2.833 & .387 & 10.202 \\
& & & & & & \\
\hline
\end{tabular}

Multiple regression results shown in table IV of the total sample which reveals that gender is a predictor of hope pathway and $15 \%$ of variance is accounted by gender for hope pathway.

Table Vii : Regression Summary (Dependent Variable- Hope Agency)

\begin{tabular}{|l|l|l|l|l|l|l|}
\hline Predictor & $\mathbf{R}$ & $\mathbf{R}^{\mathbf{2}}$ & Adjusted $\mathbf{R}^{\mathbf{2}}$ & $\mathbf{B}$ & $\boldsymbol{\beta}$ & $\mathbf{F}\left(\right.$ for $\mathbf{R}^{\mathbf{2}}$ ) \\
\hline Resilience & .320 & .103 & .087 & .123 & .320 & 6.630 \\
& & & & & & \\
\hline
\end{tabular}

Multiple regression results shown in table VII of the total sample which reveals that resilience is a predictor of hope agency and $10 \%$ of variance is accounted by resilience for hope agency.

Table Viii: Regression Summary (Dependent Variable- Resilience)

\begin{tabular}{|l|l|l|l|l|l|l|}
\hline Predictor & $\mathbf{R}$ & $\mathbf{R}^{2}$ & Adjusted $\mathbf{R}^{2}$ & $\mathbf{B}$ & $\boldsymbol{\beta}$ & $\mathbf{F}\left(\right.$ for $\mathbf{R}^{2}$ ) \\
\hline HA & .320 & .103 & .087 & .835 & .320 & 6.630 \\
& & & & & & \\
\hline
\end{tabular}


Multiple regression results shown in table VIII of the total sample which reveals that hope agency is a predictor of resilience and $10 \%$ of variance is accounted by hope agency for resilience.

\section{REFERENCES}

Aldwin, C.M., Sutton, K.J., Lachman M. (1996). The development of coping resources in adulthood. Journal of Personality ,64; 837-871.

Anthony, E.J. (1987) Risk, vulnerability, and resilience. The invulnerable child. Guilford Press; New York: 3-48.

Aspin wall, L.G. (1998) Rethinking the role of positive affect in self-regulation. Motivation and Emotion, 22;1-32.

Aspinwall, L.G.(2001). Dealing with adversity: Self-regulation, coping, adaptation, and health. In: The Blackwell handbook of social psychology, 591-614.

Block JH, Block J.(1980) The role of ego-control and ego-resiliency in the origination of behavior. The Minnesota Symposia on Child Psychology, 13; 39-101.

Block, J. Kremen, A.M. (1996). IQ and ego-resiliency: Conceptual and empirical connections and separateness. Journal of Personality and Social Psychology, 70; 349-361.

Carver, C.S. (1998). Resilience and thriving: Issues, models and linkages. Journal of Social Issues, 54; 24-45.

Folkman, S. (1997). Positive psychological states and coping with severe stress. Social Science and Medicine, 45; 1207-1221.

Folkman, S. \& Moskowitz, J.T.(2000). Positive affect and the other side of coping. American Psychologist, 55; 647-654.

Fredrickson, B.L. (1998). what good are positive emotions? Review of General Psychology, 2; 300-319.

Fredrickson, B.L. (2000). Cultivating positive emotions to optimize health and well-being. Prevention and Treatment,231-32.

Fredrickson, B.L. (2001). The role of positive emotions in positive psychology: The broadenand-build theory of positive emotions. American Psychologist, 56; 218-226.

Fredrickson, B.L. (2002). Positive emotions. In: Snyder CR, Lopez SJ, editors. Handbook of positive psychology. Oxford University Press; New York: 120-134.

Fredrickson, B.L. \& Joiner, T. (2002). Positive emotions trigger upward spirals toward emotional well-being. Psychological Science.13; 172-175.

Baron, R. M., \& Kenny, D. A. (1986). The moderator-mediator variable distinction in social psychological research: Conceptual, strategic, and statistical considerations. Journal of Personality and Social Psychology, 51, 1173-1182.

Maddi, S. R. (1970). The search for meaning. In M. Page (Ed.), Nebraska symposium on motivation. 137-186.

Maddi, S. R. (1998). Creating meaning through making decisions. The human quest for meaning: A handbook of psychological research and clinical application, 3-26. 
Mascaro, N., \& Rosen, D. H. (2005). Existential meaning's role in the enhancement of hope and prevention of depressive symptoms. Journal of Personality, 73; 985-1013.

Nolen-Hoeksema, S., McBride, A., \& Larson, J. (1997). Rumination and psychological distress among bereaved partners. Journal of Personality and Social Psychology, 72, 855-862.

Park, C. L., \& Folkman, S. (1997). Meaning in the context of stress and coping .Review of General Psychology, 30, 115-144.

Patrick, C. J., Curtin, J. J., \& Tellegen, A. (2002). Development and validation of a brief form of the Multidimensional Personality Questionnaire. Psychological Assessment, 14, 150163. 